This item was submitted to Loughborough's Research Repository by the author.

Items in Figshare are protected by copyright, with all rights reserved, unless otherwise indicated.

\title{
An exploration of the organisational stressors encountered by international disability footballers
}

PLEASE CITE THE PUBLISHED VERSION

https://doi.org/10.1080/02640414.2020.1815956

PUBLISHER

Taylor \& Francis

VERSION

AM (Accepted Manuscript)

PUBLISHER STATEMENT

This is an Accepted Manuscript of an article published by Taylor \& Francis in Journal of Sports Sciences on 2 September 2020, available online: http://www.tandfonline.com/10.1080/02640414.2020.1815956.

\section{LICENCE}

CC BY-NC-ND 4.0

\section{REPOSITORY RECORD}

Whittingham, Jon, Jamie Barker, Matthew Slater, and Rachel Arnold. 2020. "An Exploration of the Organisational Stressors Encountered by International Disability Footballers”. Loughborough University. https://hdl.handle.net/2134/12860045.v1. 
11 Author Note: ${ }^{1}$ JW Sport Consultancy Ltd, UK; ${ }^{2}$ School of Sport, Exercise and

12 Health Sciences, Loughborough University, Loughborough, LE11 3TU, UK; ${ }^{3}$

13 School of Life Sciences and Education, Staffordshire University, Leek Road, Stoke-

14 on-Trent, ST4 2DF, UK. ${ }^{4}$ Department for Health, Centre for Motivation and Health

15 Behaviour Change, Bath University, Claverton Down, Bath, BA2 7AY, UK.

16

17 Correspondence address: Jamie Barker, School of Sport, Exercise and Health

18 Sciences, Loughborough University, Loughborough, LE11 3TU, UK, Tel +44 01509

19226 302. Electronic mail may be sent to j.b.barker@1boro.ac.uk).

An exploration of the organisational stressors encountered by international 
24

25

26

27

28

29

30
Date of Submission: $11^{\text {th }}$ September 2018

Date of Re-Submission: $17^{\text {th }}$ August 2020

Word count: 6401 


\section{Abstract}

Presently, disability athletes remain under-represented in organisational

33 stressor research. Our study sought to bring novel insights to this area by

34 determining the organisational stressors experienced by international disability

35 footballers. Twelve current international disability footballers (10 male, 2 female)

36 from a range of UK impairment squads took part in the study. Semi-structured

37 interviews were completed with each participant, and data were analysed by content

38 analysis procedures. Organisational stressors data were abstracted into Arnold,

39 Wagstaff, Steadman, and Pratt's (2017) concepts, and Arnold and Fletcher's (2012)

40 four general dimensions: leadership and personnel issues, cultural and team issues,

41 logistical and environmental issues, and performance and personal issues, revealing a

42 series of football specific nuances. Our study is the first exploration of the

43 prevalence of organisational stressors within international disability football. Our

44 study also provides practitioners with an understanding of the common and unique

45 organisational stressors faced by international disability footballers. Finally, we

46 suggest a series of practical recommendations for policy development within

47 disability football organisations to aid athletes to effective manage organisational

48 stressors.

49 Keywords: elite, para-athletes, Paralympic, performance, soccer, stress 
An exploration of the organisational stressors encountered by international

In elite sport, athletes are typically exposed to a number of stressors at a personal-

59 level (e.g., an athletes' own performance expectations) and at an organisational-level

60 (e.g., environmental factors) that can subsequently affect their health (e.g., Tabei,

61 Fletcher, \& Goodger, 2012) and performance (e.g., Arnold, Fletcher, \& Daniels,

2017). An important avenue of stress research relates to organisational stressors,

which are defined as being the environmental demands associated with an

organisation in which an individual operates (Fletcher, Hanton, \& Mellalieu, 2006).

65 Evidence indicates the importance of these stressors in that elite athletes have been

66 found to experience and recall more demands associated directly with their sport

67 organisation than with their competitive performances (e.g., Hanton, Fletcher, \&

68 Coughlan, 2005).

Extant literature into organisational stressors has sought to provide insight

70 into the range of positive (Fletcher et al., 2006; Fletcher, Hanton, \& Wagstaff, 2012)

71 and negative outcomes associated with organisational stressors across a range of

72 facets including emotions, behaviours (e.g., overtraining), psychological well-being,

73 and underperformance (e.g., Fletcher et al., 2012). To explain these effects, Fletcher

74 et al.'s (2006) meta-model of stress, emotions and performance suggests: "stressors

75 arise from the environment the performer operates in, are mediated by the processes

76 of perception, appraisal and coping, and, as a consequence, result in positive or

77 negative responses, feeling states, and outcomes" (p. 333). Using this current meta-

78 model of stress as a backdrop, our study intentionally does not examine the effects or

79 coping mechanisms used by players to deal with the stressors encountered. But

80 instead, and given the paucity of research within disability football, we offer an 
81 insight into the peformance environment the athletes operate in and their perceptions

82 of organisational stressors encountered (Fletcher et al., 2006). We anticipated that taking this particular lens will provide a springboard for future researchers to explore other key aspects of the meta-model of stress within disability football (e.g., extensively within organizational stress work in sport. Specifically, more recent findings have demonstrated the links between appraisal of, and influence of, organisational stressors upon performance (e.g., Didymus \& Fletcher, 2017b), the range of emotional consequences if stressors persist (e.g., Rumbold, Fletcher, \&

91 Daniels, 2018) and how dealing with stressors may impact upon future playing time

92 (e.g., Rumbold, Fletcher, \& Daniels, 2020). Despite this emerging literature, studies

93 with disabled athletes remain comparatively limited. With an ever-increasing

94 number of disabled athletes at major sport competitions such as the Paralympic

95 Games, researchers have outlined the importance of understanding this population

96 group, and the potentially unique organisational stressors that they encounter, to aid

97 with supporting athletes, coaches and practitioners in achieving a more optimal stress

98 experience (i.e., Arnold, Wagstaff, et al., 2017; Rumbold et al., 2018).

To date, the most comprehensive study exploring the prevelance of

100 organisational stressors within disability sport was conducted by Arnold, Wagstaff,

101 et al. (2017). In contrast to previous literature (e.g., Dieffenbach \& Statler, 2012),

102 this study reported a number of salient similarities (e.g., selection processes) and

103 differences (e.g., classification, lack of crowds, coaches being unaware of tailoring

104 exercises, lack of knowledge) between the experiences of British disabled athletes

105 compared to non-disabled athletes. In addition, findings from studies conducted 
106 with Canadian (i.e., Allan, Smith, Côte, Ginis, \& Latimer-Cheung, 2018) and

107 Kenyan para-athletes (Crawford \& Stodolska, 2008) have identified comparable

108 considerations including a lack of financial resources, coaching, and negative

109 attitudes towards disability. Overall, this research provides an important foundation

110 to develop from and adds to previous evidence that has explored other forms of

111 stressors experienced by disabled athletes, such as social and policial issues (e.g.,

112 Bush, Silk, Porter, \& Howe, 2013).

113 While Arnold and colleagues' (2017) findings develop the breadth of our

114 understanding by focusing on eight sports and a range of disabilities, there is a need

115 to gain a more detailed understanding within a specific sport to begin the

116 development of evidence-based interventions tailored to the nuances of specific

117 sports. By studying a range of disabiltities within a single sport we are better able to

118 understand the contextual naunces (including intra-group differences and

119 similarities) and the unique culture at play. Although some studies have examined

120 disabled athletes within the same sport (e.g., Campbell \& Jones, 2002), such studies

121 have not specifically focused upon exploring the organisational stressors that the 122 athlete encounters.

123 One sport absent from previous research is that of disability football.

124 Football is one of the most popular global sports and although previous

125 investigations have explored organisational stressors within football across a range

126 of contexts at the highest levels of the game (e.g., Kristiansen, Ivarsson, Solstad, \&

127 Roberts, 2019), none have specifically focussed upon disability football at any level

128 of participation.

129 Disability sport is governed according to the International Sport Federation

130 (ISF) criteria relevant to each impairment group. One example of a unique stressor 
131 disabled athletes are subject to is the ongoing and evolving eligibility checks

132 according to the impairment specific ISF, a criterion not encountered within non-

133 disability football. Disability football is the seventh highest participated team sport

134 in England (Sport England, 2015), placing it above more established non-disability

135 sports (e.g., rugby league) although below male and female football. Despite

136 significant investment into disability football over the previous 20 years via a

137 number of stakeholders, the amount of funding available remains comparatively very

138 low to the non-disabled game which is able to attract significant sponsorship

139 investment. Consequently, although both male and female football involvement has

140 seen significant developments in their playing structures in recent years (for instance,

141 through the introduction of the Elite Player Performance Plan in the boy's academy

142 system in 2012 and the professionalisation of women's pyramid system resulting in

143 full-time contracts for those in the Women's Super League in 2011), disabled

144 footballers have to juggle the demands of working full-time outside of football as

145 they seek to progress to the pinacle of their sport. The experiences that disability

146 footballers encounter therefore are likely to be unique within the wider sport context

147 and potentially create novel demands for performers particuarly as the public

148 awareness of disability football, and sport, increases.

149 Evidently, organisational stressors are experienced by elite disabled athletes

150 (Arnold, Wagstaff, et al., 2017), but presently there is limited understanding of the

151 organisational stressors prevalent within the novel context of UK international

152 disability football. Using Arnold and Fletcher's (2012) framework as an

153 underpinning, the purpose of our current study was to understand the organisational

154 stressors experienced by international disability footballers. While not a central aim

155 of our study, we also sought to provide data which may enable national govening 
175 \& Sparkes, 2008).

\section{Participants}

\section{Approach}

bodies (NGBs) and key stakeholders (e.g., coaches and sport science practitioners) working within disability football (and in other sports) to create effective organisational structures including an optimal stress environment.

\section{Method}

Underpinning our investigation are philosophical assumptions of ontological relativism (i.e., reality is mind dependent and multiple) and epistemological postpositivism (i.e., knowledge is multiple rather than singular; see Creswell, 2013). Given our focus upon organisational stressors and the population under study, it is pertinent to consider any analysis from the perspective of the participant given that previous researchers have indicated the importance of understanding experience from the perspective of the disabled athlete as each athlete will 'experience' their disability uniquely (e.g., Smith, Bundon, \& Best, 2016). A qualitiative methodology was deemed best suited for this investigation in view of the limited literature examining organisational stressors in disability sport (Silverman, 2006).

Specifically, interviews were chosen to encourage participants to provide indepth information based on their first-hand experiences and thereby allow participants to express their individual identities as a part of their personal story which is developed according to the cultural parameters they operate within (Smith Participants were selected via purposive sampling techniques to ensure representation from across the NGB international disability squads and impairment spectrum. Participants were required to have a classified disability (confirmed by their NGB and ISF) and be a current member of an international disability football 
squad. As part of their preparations for a yearly major competition, the participants were training two days each month within the environment of their international squad While they were also expected to follow both a strength and conditioning programme provided centrally from the NGB as well as partaking in regular football activities within club football. All participants were interviewed prior to their next major competition with the sample comprising 12 footballers (10 male, 2 female), ranging in age from 19 to $33\left(M_{\mathrm{age}}=25.50 \pm 3.58\right)$, who had been international athletes for an average of $5.92( \pm 3.20)$ years. Two starting footballers were included from each of the following squads: blind, cerebral palsy, deaf male, deaf female, partially sighted, and wheelchair football teams. All participants within the sample were part-time athletes and not paid for their involvement within their squad or to compete within their global competition cycle.

\section{Procedure}

Following institutional ethics approval, players eligible for the study were contacted to take part in the research and were informed about the study, what their involvement would entail and their participatory rights (covering aspects such as confidentiality, anonymity, and their right to withdraw) before arranging a convenient time and location for the interview. An interview guide was developed to explore the topics pertinent for disability footballers with a copy of the guide provided to the players one week prior to the interview to allow them to consider their responses more fully for the interview. Pilot interviews were conducted prior to the main study with two recently retired (less than two years) players to check the appropriatess of the interview guide, and allow the interviewer to refine questioning techniques. Based upon the pilot interviews, several further probes (e.g., "What effect do you think that had?") were devised to support with clarifying and 
206 elaborating on the player's perspectives (cf. Biddle, Markland, Gilbourne,

207 Chatzisarantis, \& Sparkes, 2001). Each player provided informed consent prior to

208 the start of data collection. Interviews $\left(M_{\text {minutes }}=88.56 \pm 16.68\right)$ were conducted

209 face-to-face or via FaceTime to account for the preference of the interviewee (i.e.,

210 offering access to an interpreter for deaf participants), were digitially recorded, and

211 transcribed verbatim.

212 Interview Guide

213 A five section interview guide was developed. The first section outlined to

214 the participants the study focus and their participatory rights. The second section

215 encompassed a series of questions to develop rapport with the player, for instance,

216 "Tell me what you consider to be one of your major achievements so far in football"

217 and "Tell me how your first call up to the [country] squad came about". The third

218 section defined organisational stressors to check the players' understanding

219 regarding the focus of the study. The fourth section included questions exploring the

220 players' experiences of organisational stressors in their squad, for instance, "Tell me

221 about your training schedule during your last tournament", "Talk to me about the

222 different personnel working with the squad", "What can you tell me about the

223 support players receive" and "Tell me about the team's goals and how they were

224 determined". The final section allowed players to discuss additional issues they

225 wished to raise which had not been already covered.

226 Data Analysis

In analysing the data, we used Fletcher et al.'s (2006) definition of

228 organisational stressors to provide the basis for that which should be coded as a

229 'stressor'. The interview transcripts were manually analysed using inductive and

230 deductive content analysis procedures (Weber, 1985). Specifically, environmental 
231 demands associated primarily and directly with the NGB within which the disability

232 footballer was operating were firstly identified (e.g., organisational stressors). The

233 analysis process involved the interviewer reading, re-reading, and listening to the

234 transcripts and coding the raw-data threads deductively into the concept groupings,

235 themes, and general dimensions as presented within Arnold and Fletcher (2012) and

236 Arnold, Wagstaff et al. (2017). These were: (1) leadership and personal issues; (2)

237 cultural and team issues; (3) logistical and environmental issues; and (4)

238 performance and personal issues. Constant comparative methods were used

239 throughout the analysis process to compare stressors and anecdotes for any

240 similarities, variations, or differences, as well as comparing across the analysis levels

241 (e.g., stressors to concepts, concepts to concepts; Holt \& Tamminen, 2010). At each

242 stage of the deductive analysis, discussions with critical friends were completed

243 before continuing the analysis to the next stage. Where new concepts emerged, these

244 were inductively labelled before being deductively placed into the appropriate theme

245 and general dimension grouping in accordance with Arnold and colleagues' (2012;

246 2017) findings.

247 Reflexivity and Methodological Rigour

248 In view of the nature of the study, our approach centred upon a relativist

249 position (Smith \& McGannon, 2018; Sparkes \& Smith, 2009) in that views are

250 relative to differences in perception from the participants' own experiences of

251 disability. Further, consideration also has to be given to the potential for the

252 experiences and background of the primary researcher that had the potential to

253 influence the data collection, analysis, and subsequent presentation of findings.

254 Several steps were taken to enhance the trustworthiness of the findings. First, an

255 audit trail was maintained and shared with the second and third authors throughout 
the analysis process to consider the thematic ideas interpreted. Second, a critical

257 friend was engaged with in order to challenge the decisions being made and

258 encourage reflection of alternative interpretations (cf. Smith \& McGannon, 2018).

259 Third, within the Results and Discussion, content codes are accompanied by

260 contextually rich, direct quotations to enable readers to make their own meaningful

261 interpretations of the data (cf. Biddle et al., 2001; Smith \& McGannon, 2018).

\section{Results and Discussion}

In total, 428 organisational stressors were interpreted from the data that were

264 then abstracted into the concepts detailed by Arnold, Wagstaff et al. (2017) and

265 reviewed in-line with Arnold and Fletcher's (2012) four general dimensions: (1)

266 leadership and personnel issues; (2) cultural and team issues; (3) logistical and

267 environmental issues; and (4) performance and personal issues. Leadership and

268 personnel issues encapsulate organisational stressors associated with management

269 and support of a sports team (see Figure 1). Cultural and team issues encapsulate the

270 organisational stressors associated with attitudes and behaviours within the sports

271 team. Logistical and environmental issues encapsulate organisational stressors

272 associated with the organisation of operations for training and/or competition.

273 Finally, performance and personal issues encapsulate the organisational stressors

274 associated with a performer's athletic career and physical self (Arnold \& Fletcher,

275 2012). Within each general dimension, we have identified nuances specific to the

276 relativist experiences of international disability footballers, and football as a sport,

277 that extends the insights provided in previous research (i.e., Arnold et al., 2017). Full

278 analysis of the data is available on request from the first author.

279 Leadership and Personnel Issues 

pressures, playing experience within the squad, the governing body, media profile, and game officials. We found that athletes had concerns regarding the availability of specialist team staff which specifically related to how the functional efficiency of the team was impacted when key medical personnel were unavailable. Further to this, we also found the players' perceptions of favouritism within the NGB towards nondisability over elite disability squads was a key stressor identified. Previous research on performance environments has noted how athlete performance can be negatively

289 impacted through both team management factors in non-disability (e.g., Arnold,

290 Collington, Manley, Rees, Soanes, \& Williams, 2019) as well as disability settings

291 (e.g., Crawford \& Stodolska, 2008), and the salience of coach leadership skills on

292 and off the pitch (e.g., Allan et al., 2018). Furthermore, the favouritism towards

293 non-disability football teams relative to the disability teams within the same NGB is

294 a novel finding in this context. An additional finding related to the players'

295 perceptions of the coach's interactions with them and, in particular, challenges

296 resulting from coaches communicating with players in their preferred language. This

297 was a consideration highlighted specifically in regards the deaf squads as one player 298 noted:

299 Without the interpreter, we wouldn't be able to even get any information 300 across but it's just that I think a lot of times, like even the coaches and the 301 manager, I'm not sure they're aware that sometimes it is second-rate 302 information that's been passed on... So it's a little bit whether the coach is 303 really getting his point across so sometimes that, like sort of, gets a bit $304 \quad$ muddled. (Participant 10) 
Indeed, previous researchers have not recruited deaf athletes (e.g., Arnold et al., 2017) and thus our finding regarding the importance of the interpreter and the apparent strain on coach-athlete relations as a result of such communications advances our understanding of disability footballers' experiences of organisational stressors.

The international disability footballers in our current study also identified the potential impact and influence of parents upon the squad players and staff as a distraction to team operations. This was particularly apparent in relation to decisions made on squad selection for competitions and the tactics and/or strategies utilised where parents had direct access to the group throughout the duration of competition. For instance, one player expressed:

So like the younger lads, their parents will come to games which is really interesting because they've probably been there now three or four years to all tournaments. So we've actually got genuine support when we go away and the other side of it is, you know, they have opinions as everyone does in football...but they have opinions that sometimes it's not that they're not right, but when everyone starts to have an opinion and you just think "That's not ideal saying that. That's gonna put something in someone's head". But they've gone out their way to come support their kid. So, you know, we have to manage parents...We're an elite squad yet the manager's managing parents so that's another bit where we, certainly senior players, try and manage it... Sometimes it could all be positive, and it's probably too positive, and you think "Humm, he didn't do that well. I wouldn't go over the top"...so it's managing them...that's a massive [impact on the staff and players], but if it [parental input] got out of hand, it'd be an absolute nightmare. (Participant 4) 
Considering this stressor, researchers have identified comparable

333 disability football academies have highlighted that parents experience organisational

334 stressors too (Harwood, Drew, \& Knight, 2010). Studies have also shown that

335 parents naturally feel empathy for their children in competitive settings (Harwood,

336 Clarke, \& Cushion, 2016) and go through several experiences associated with

337 watching their child compete (e.g., Harwood et al., 2010). Additionally, several

338 studies have indicated the increased presence and involvement of parents in sporting

339 activities where their child has a disability (e.g., Shapiro \& Malone, 2016) and the

340 impact this has upon their participation. In our study, participants are on average 25

341 years old (adults) and are still talking about their parents in relation to their football

342 performance. This data could imply that disability footballers are perhaps still, or at

343 least more, reliant on their parents for a range of football-related issues. Indeed, the

344 parental involvement and associated organisational stressors for footballers (non-

345 disabled) would stop at approximately 18 years, but our novel findings indicate that

346 for disability footballers, organisational stressors surrounding parents still prevail

347 into adulthood, and therefore have important implications for coaches and sport

348 psychologists working in international disability football.

349 In support of these findings, Ferrari (2019) has indicated that parents of

350 children with disabilities tend to be more critical than other parents. Potential

351 reasons for this parental dynamic may be that parents have differing experiences and

352 knowledge of the sport (Holt, Tamminen, Black, Sehn, \& Wall, 2008) and that

353 parents may find it difficult to manage their child's emotional-motivational levels in

354 dealing with failure (Ferrari, 2019). In our study, it is possible that players perceived 
that their parents are still developing their understanding regarding international disability football, and their parents' psychological approach may hold more in common with that of amateur youth sport than international adult environments (e.g., Knight, Berrow, \& Harwood, 2017). Through adopting dual empathetic and educational approaches with parents, therefore, NGBs and elite disability squad staff can support parents to maintain their parent-child relationships and identify how to prevent such over-protectionist tendencies occurring (i.e., Antle, Mills, Steele, Kalnins, \& Rossen, 2007) through heightening their sense of being close to the overall setup (i.e., Ferrari, 2019).

\section{Cultural and Team Issues}

Stressors identified within this theme (see Figure 1) related to teammates' personality and attitudes, cultural norms, and team atmosphere and support. One prominent observation related to the perceived sacrifices that players felt they made in relation to diet and fitness comparative to their teammates given that the squad spend very little time together. For instance, one player suggested: I mean it is hard to be motivated for some people if you're not being around the environment all the time. I can see, I can see why it would, like, some of the lads would find it hard to be motivated. I mean like, as I said, some of the lads are still quite young and young in the mind as well so like they, they so still like going out for a drink here and there and they do still like, like, they don't have the best diets...Like for me, personally I'm the sort of person that just loves the training, loves to eat well anyway so it's not really difficult for me that when a tournament comes around...Like I said, I remember coming away from [country] thinking like "We didn't do well there" because the lads, like, some of the lads have putting things on Snapchat like a week before we go and it, like annoying me, and I always 
felt like we come away and, even though you feel like yourself you could have done a little bit better, or could have worked a little bit harder leading up to it cause when you don't achieve your goals, you always, like that's the first thing you look at, thinking "What could I have done more of or better?" but then I was always sort of coming away and thinking like "The lads haven't trained as hard as", like I trained morning, noon and night for some day and you just feel like if they'd done the same, like, was it being in the same situation...we might not get the contact time together as much as we'd like but what you do away is as important, if not more. I think that kind of penny finally dropped with a few lads that they needed to go and sort themselves out a little bit...I think that's always one of the main barriers because you're not meeting up as much as you can, you need to do as much as possible away, and I know it's hard. Like everyone, we're not professional people, we've got jobs and whatever...it is hard to stay in, I know that cause I've been there. I remember going out with my mates and having to then get up at 7,8 o'clock in the morning to go strength and conditioning. And it is hard, but like for me, you're an England player and you just go and do it. Don't moan about it, you go and do it and once you're back and its out the way, it's out the way isn't it? But I mean not everyone can have that mentality. (Participant 2) The players' perceptions on this stressor tallies with research that has noted how antisocial teammate behaviours (e.g., being unwilling to partake in prescribed physical conditioning training) can negatively impact upon an athlete's sport experience in contrast to prosocial behaviours (e.g., partaking in team bonding exercises) which are positively associated with effort, performance, and enjoyment (Bruner et al., 2017). As noted by Allan et al. (2018), an athlete's sense of belonging is wrapped up within their performance and relational narratives, with possible 
interpretations based around social acceptance as well as a sense of community within the group potentially influencing performance output.

Off-field relationships can play a significant role in social support and team effectiveness (e.g., Gershgoren et al., 2015) with player relationships shown to be related to self-confidence (e.g., Freeman \& Rees, 2009) and performance in football (e.g., Gioldasis, Stavrou, Mitrotasios, \& Psychountaki, 2016). Extending Arnold, Wagstaff et al.'s (2017) observations relating to team atmosphere and support further, for one elite disability football impairment group, social cohesion (i.e., Carron, Bray, \& Eys, 2002) within the playing group was particularly prominent (e.g., Roberts, Arnold, Gillison, Bilzon, \& Colclough, 2020). This is illustrated by one participant who stated: “...when I first started it was very much the signers and the oralists. Which wasn't great (be)cause you don't want that in a team" (Participant 3), and another who noted, “... as bad as it might sound, I can hear, and like previously it was more of a deaf-based squad...so I sort of got on a bit better with the staff' (Participant 11).

Research within deaf sport and with deaf athletes signifies a key consideration relating to Deaf culture, and by association, the upbringing an individual player has had (e.g., Ammons \& Eickman, 2011). In some cases, there may be no association with Deaf culture at all; for instance, recent statistics from the National Deaf Children's Society (NDCS) show that 90\% of deaf children are born to hearing parents, with the majority of deaf children educated within mainstream education and not accessing British Sign Language during their childhood (NDCS, 2017). These findings are significant to understand communication preferences between those who sign and those who communicate orally (i.e., Atherton, 2009), and the challenges of developing social cohesion within sport teams. The literature 
430 is limited in this regard; however, one study that examines the role of football within

431 the deaf community highlights the isolation that deaf players can feel off the pitch

432 and how unfulfilling their experiences of playing can be (Atherton, Russell, \&

433 Turner, 2001). The insights from the deaf footballers in the current study highlight a

434 stressor associated with encouraging deaf and hearing-impaired players volition to

435 work together (social and task-related).

436 Logistical and Environmental Issues

Stressors identified within this theme (see Figure 1) related to facilities and

438 equipment, rules and regulations, travel, weather conditions, structure of training,

439 competition format and selection. Selection was a prominent concept across all

440 squads and specifically, two strands emerged relating to the identification of new

441 players as well as selection into squads. Participants highlighted the lack of

442 prospective players being identified to suitably challenge players within the current

443 squad, as highlighted by one player who said: "It's not competitive at all to be

444 honest. You kind of, without sounding big headed, you kind of know you're pretty

445 much in the squad" (Participant 3). The apparent lack of a deeper player pool led to

446 further stressors regarding the perceived disparity in team selection policy as

447 illustrated here:

448 I've seen like other players turn up late to, half a day late, leave half a day early 449 since then they maybe are a bit more of a valuable player on the pitch and 450 nothing happens with that...There are untouchable players in the squad. 451 Definite, definite untouchable players in the squad. (Participant 6)

452 Similarly, stressors associated with classification were also raised with

453 participants in the current study viewing the process as stressful from several

454 perspectives. For instance, one stressor related to a new classification process which 
455 was due to be implemented within cerebral palsy football, While another stressor

456 related to being reclassified ahead of a competition in partially sighted football:

457 I've been classified three times...you're just thinking "Oh my god, I just

458 want to get this out the way" because it's very hard to focus on the

459 tournament when you've got that in mind. (Participant 2)

460 A further stressor related to the perceived limited availability and use of the

461 current NGB training kit. A particular part of this stressor was how the kit was

462 comparatively available to and used by the non-disability squads despite all

463 international squads being grouped within the same NGB operational matrix to

464 receive centralised support: ...when we've turned up and we've got the old, you know, last season's kits and stuff like that...You wouldn't give any other [NGB] squad these...that's more the stress side for me, because I think we're [country]...we're going to represent the country, we're representing the [NGB] so why not put us out in the newest of gear...instead of having us wearing last seasons and, it's more of a morale thing as well for the lads. (Participant 9)

472 morale, has not been identified in previous studies of disability athletes (Arnold,

473 Wagstaff, et al., 2017). One potential rationale for this being perceived as a stressor 474 may be contextualised from the perspective of the social identity approach (Tajfel \& 475 Turner, 1979). To elaborate, previous researchers have shown that elite disability 476 athletes desire to be recognised first and foremost as an athlete (Purdue \& Howe, 477 2012). However, international disability football players in the current study felt that 478 being unable to use the same training kit as the elite non-disability squads results in 
479 the players perceiving themselves to be part of an out-group rather than an in-group

480 within the NGB setup.

481 Further, investigations of Team GB at the London 2012 Olympic Games

482 identified team kit to be a salient factor in the development of team identity,

483 particularly in highlighting in-group characteristics comparative to other groups

484 (Slater, Barker, Coffee, \& Jones, 2015). The authors note that the use of a single

485 team kit resulted in the development of a single organisational entity spanning across

486 teams under Team GB. One comparable element which can be drawn between Team

487 GB and the NGB elite squads in the current study are that both organisations operate

488 within high performance environments. Further, Allan et al. (2018) identified within

489 their review the notion of belongingness as one of several experiential elements of

490 participation, and noted the inconsistencies perceived by individual athletes in the

491 way each of these elements is experienced and can impact upon their sporting

492 involvement. However, in contrast with this study and Slater et al.'s (2015) findings,

493 the perceptions of the disability footballers in the current study indicate that they do

494 not recognise themselves as being a part of the same organisational entity as the elite

495 non-disability squads, and therefore the potential psychological benefits to enhance

496 performance may not be present (cf. Høigaard et al., 2013).

497 Performance and Personal Issues

498 Stressors identified within this theme (see Figure 1) related to finances,

499 injuries, and diet and hydration. Players highlighted several concerns relating to

500 financial considerations, such as apprehension at a loss of earnings While with their

501 squad as a result of having to take time off from their job. For example, one player

502 noted: 

... that was a big stress I had, just the financial side because it was just not worth ... it wasn't financially viable for me to turn up to training camps and then miss work and not get paid for it. (Participant 9) Equally, a prominent stressor for players centred around injury support away from elite squad settings. Researchers have reported that injury rates are comparable to those in non-disability sport and that injury is a significant stressor for disabled athletes (Fagher et al., 2016). One reason for this relates to the potential for an injury to pose additional limitations on a disabled athlete and their everyday activities (Weiler, van Mechelen, Fuller, \& Verhagen, 2016). Although international disability sport is now viewed comparably to international non-disability setups (e.g., Fagher et al., 2016), the majority of the elite disability footballers do not have fulltime contracts and undertake their preparations away from formal training camps. Consequently, players are potentially more likely to incur an injury in their homesetting. Previous researchers have shown that being unable to access a trusted medical professional may lead to increased stress and anxiety levels (e.g., Podlog, Dimmock, \& Miller, 2011) however identifying appropriate medical support can be challenging for disabled athletes (Ahmed et al., 2015), as one player observed: I've had a few injuries in the past where it's really hard to get support if you can't prove you did [it] While at [nation]....anything we get injured by doing is stuff we're doing away in preparation for [nation]. You know, you're an [nation] player 12 months of the year. (Participant 4)

A further stressor related to the availability of lifestyle development support, particularly given the majority of elite disability footballers are not full-time athletes. The players' concerns related to the appropriateness of aspects such as following ascribed fitness programmes to fit in alongside their full-time employment 
528 obligations: “Sometimes [staff member's] programme's a bit unrealistic with [their]

529 morning and afternoon sessions. That's probably based more around a pro-football

530 player or a player that doesn't work" (Participant 6). It may be that support staff with

531 a background in football are not perceived to tailor their programme optimally for

532 disability footballers in terms of time management.

Our findings identify novel and key stressors which have not been previously

534 reported in the literature (e.g., communication barriers between hearing coaches and

535 deaf players; parental influence on and around the squad; players' perceptions of

536 their teammates lifestyle in preparing for squad activities; and a perceived lack of

537 identity with and to the other NGB squads). This study, therefore, not only

538 contributes to knowledge in this area, but also can inform applied practice in

539 international disability football. While some stressors encountered were similar to

540 those previously reported with non-disabled athletes (e.g., injury support), other

541 stressors were similar to disability specific ones identified previously (e.g.,

542 classification); thus, providing further evidence to the prevalence of organisational

543 stressors within sporting environments.

544 Applied Implications

546 interventions within sport organizations (i.e., Moore, Freeman, Hase, Solomon-

547 Moore, \& Arnold, 2019), our study provides a number of applied implications which

548 may aid this venture. First, the findings illuminate a need to educate parents in

549 regards to their involvement and support of disability footballers (Gould, Lauer,

550 Rolo, Jannes, \& Pennisi, 2008). This is a novel finding, and is particularly pertinent

551 to parents who may feel unfamiliar with an international disability environment, and

552 this could be achieved through educational workshops through the NGB (e.g., 
553 Knight et al., 2017). Second, national team identity-specific stressors could be

554 reduced through embracing a shared team identity between elite disability and non-

555 disability teams, initiated by and through the NGB (i.e., Slater et al., 2015). This

556 could include access to National Training Centres for entire squad training and

557 competition camps and using the same national kit for preparations and

558 competitions. Third, to alleviate stressors relating to coach-player communication in

559 football, clear short- (e.g., professional development opportunities), and long-term

560 (e.g., mentoring schemes) solutions need to be presented. Fourth, the findings from

561 this study provide supporting evidence for key NGB staff to use in seeking to

562 influence internal policy. It may be prudent for football governing bodies to garner

563 additional support within their organisation for elite disability teams centred upon

564 organisational stressors that players are prone to, as found in our study, and which

565 may negatively impact upon performance (i.e., Rumbold et al., 2018).

566 Limitations and Future Researcher Directions

567 Regarding shortcomings of this study, first it is important to emphasise that

568 the findings may only be specific to the organisation sampled or to disability football

569 provision at the international level. However, it is possible that other athletes and

570 NGBs may have encountered similar issues to those discussed, and thus may benefit

571 from the findings and their implications. Second, the study focused on international

572 disability footballers, and female athletes were under-represented as a result of the

573 NGB elite squad structures. The data presented supports the notion that certain

574 stressors are unique to certain groups and contexts (i.e., Kristiansen et al., 2012).

575 Specifically within elite disability football, investigations may be directed towards

576 developing deeper understanding of the potential variance of stressors reported by

577 different impairment groups and genders (e.g., Atherton et al., 2001), and to the 
578 effects of coping mechanisms utilised by players (i.e., Kristiansen et al., 2012).

579 Further, investigations of organisational stressors within elite disability football from

580 other countries may offer an opportunity to explore the stressors within different

581 cultures (i.e., Arnold, Ponnusamy, Zhang, \& Gucciardi, 2017). Finally, we provide

582 our interpretation of the organisational stressors experienced by international

583 disability footballers. Other researchers, particularly with different philosophies

584 (e.g., an interpretivist position), may have interpreted these disability footballer

585 experiences differently.

586 Conclusion

587 Our study is the first to explore the organisational stressors experienced by

588 international disability footballers across all impairment squads within a single NGB.

589 The study enhances awareness and understanding of the first stage of Fletcher et al.'s

590 (2006) meta model, that is the stressors component within the P-E fit stage.

591 Specifically, it helps to understand from a theoretical standpoint, which stressors

592 might arise for international disability footballers, which is a fundamental first step

593 before the rest of the meta model can then be applied (e.g., appraisal, coping etc).

594 While the findings illustrate similarities with previous researchers sampling disability

595 athletes (i.e., Arnold, Wagstaff, et al., 2017), they also advance understanding by

596 highlighting novel organisational stressors experienced by disabled international

597 footballers, including: (1) the overreliance on parental support into adulthood; (2) a

598 lack of continuity in kit across all football squads and potential for a shared social

599 identity to be developed across the NGB and; (3) ineffective communication

600 strategies.

601 Conflicts of interest: None. This research did not receive any external funding. 


\section{References}

Ahmed, O. H., Hussain, A. W., Beasley, I., Dvorak, J., \& Weiler, R. (2015). Enhancing performance and sport injury prevention in disability sport: Moving forwards in the field of football. British Journal of Sports Medicine, 49, 566-567. DOI: 10.1136/bjsports-2013-093058

Allan, V., Smith, B., Côte, J., Martin Ginis, K. A., \& Latimer-Cheung, A. E. (2018). Narratives of participation among individuals with physical disabilities: A life-course analysis of athletes' experiences and development in parasport. Psychology of Sport \& Exercise, 37, 170-178. DOI: 10.1016/j.psychsport.2017.10.004

Ammons, D. \& Eickman, J. (2011). Deaflympics and the Paralympics: Eradicating misconceptions. Sport in Society, 14, 1149-1164. DOI:

$10.1080 / 17430437.2011 .614772$

Antle, B. J., Mills, W., Steele, C., Kalhins, I., \& Rossen, B. (2007). An exploratory study of parents' approaches to health promotion in families of adolescents with physical disabilities. Child: Care, Health and Development, 34, 185193. DOI: $10.1111 / \mathrm{j} .1365-2214.2007 .00782 . \mathrm{x}$

Arnold, R., Collington, S., Manley, H., Rees, S., Soanes, J., \& Williams, M. (2019). “The team behind the team": Support staffs' experiences of organizational stressors in elite sport. Journal of Applied Sport Psychology, 31, 7-26. DOI: DOI: $10.1080 / 10413200.2017 .1407836$

Arnold, R., \& Fletcher, D. (2012). A research synthesis and taxonomic classification of the organizational stressors encountered by sport performers. Journal of Sport and Exercise Psychology, 34, 397-429. DOI: 10.1123/jsep.34.3.397 
Arnold, R., Fletcher, D., \& Daniels, K. (2017). Organizational stressors, coping, and outcomes in competitive sport. Journal of Sports Sciences, 35, 694-703. DOI: $10.1080 / 02640414.2016 .1184299$

Arnold, R., Ponnusamy, V., Zhang, C. Q., \& Gucciardi, D. F. (2017). Cross cultural validity and measurement invariance of the Organizational Stressor Indicator for Sport Performers (OSI-SP) across three countries. Scandinavian Journal of Medicine and Science in Sports, 27, 895-903. DOI: 10.1111/sms.12688

Arnold, R., Wagstaff, C. R. D., Steadman, L., \& Pratt, Y. (2017). The organisational stressors encountered by athletes with a disability. Journal of Sports Sciences, 35, 1187-1196. DOI: 10.1080/02640414.2016.1214285

Atherton, M. (2009). A feeling as much as a place: Leisure, deaf clubs and the British deaf community. Leisure Studies, 28, 443-454. DOI: $10.1080 / 02614360902951690$

Atherton, M., Russell, D., \& Turner, G. (2001). More than a match: The role of football in Britain's Deaf community. Soccer and Society, 2, 22-43. DOI: $10.1080 / 714004857$

Biddle, S. J., Markland, D., Gilbourne, D., Chatzisarantis, N. L., \& Sparkes, A. C. (2001). Research methods in sport and exercise psychology: Quantitative and qualitative issues. Journal of Sports Sciences, 19, 777-809. DOI: $10.1080 / 026404101317015438$

Bruner, M. W., Boardley, I., Allan, V., Forrest, C., Root, Z., \& Côté, J. (2017). Understanding social identity and intrateam moral behaviour in competitive youth ice hockey: A narrative perspective. The Sport Psychologist, 31, 173186. DOI: $10.1123 /$ tsp.2015-0117 
651

652

653

654

655

656

657

658

659

660 661

662

663

664

665

666

667

668

669

670

671

672

673

Bush, A., Silk, M., Porter, J., \& Howe, P. D. (2013). Disability [sport] and discourse: Stories within the Paralympic legacy. Reflective Practice, 14, 632-647. DOI: $10.1080 / 14623943.2013 .835721$

Campbell, E., \& Jones, G. (2002). Sources of stress experienced by elite male wheelchair basketball players. Adapted Physical Activity Quarterly, 19, 8299. DOI: 10.1123 apaq.19.1.82

Carron, A. V., Bray, S. R., \& Eys, M. A. (2002). Team cohesion and team success in sport. Journal of Sport Sciences, 20, 119-126. DOI:

$10.1080 / 026404102317200828$

Crawford, J. L., \& Stodolska, M. (2008). Constraints experienced by elite athletes with disabilities in Kenya, with implications for the development of a new hierarchical model of constraints at the societal level. Journal of Leisure Research, 40, 128-155. DOI: 10.1080/00222216.2008.11950136

Creswell, J. W. (2013). Qualitative inquiry and research design: Choosing among five approaches $\left(3^{\text {rd }} \mathrm{Ed}\right.$.). London, UK: Sage.

Didymus, F. F., \& Fletcher, D. (2017a). Effects of a cognitive-behavioural intervention on field hockey players' appraisals of organizational stressors. Psychology of Sport and Exercise, 30, 173-185. DOI: 10.1016/j.psychsport.2017.03.005

Didymus, F. F., \& Fletcher, D. (2017b). Organizational stress in high-level field hockey: Examining transactional pathways between stressors, appraisals, coping and performance satisfaction. International Journal of Sports Science \& Coaching, 12, 252-263. DOI: 10.1177/1747954117694737 
674 Dieffenbach, K. D., \& Statler, T. A. (2012). More similar than different: The psychological environment of Paralympic sport. Journal of Sport Psychology in Action, 3, 109-118. DOI: 10.1080/21520704.2012.683322

Fagher, K., Forsberg, A., Jacobsson, J., Timpka, T., Dahlström, O., \& Lexell, J. (2016). Paralympic athletes' perceptions of their experiences of sports-related injuries, risk factors and preventive possibilities. European Journal of Sport Science, 16, 1240-1249. DOI: 10.1080/17461391.2016.1192689

Ferrari, L. (2019). Insights from parents of children and young adults with and without disability who play sports. Interdisciplinary Journal of Family Studies, 24, 1-15.

Fletcher, D., Hanton, S., \& Mellalieu, S. D. (2006). An organizational stress review: Conceptual and theoretical issues in competitive sport. In S. Hanton \& S. D. Mellalieu (Eds.), Literature reviews in sport psychology (pp. 321-373). New York, NY: Nova Science Publishers.

Fletcher, D., Hanton, S., \& Wagstaff, C. R. D. (2012). Performers' responses to stressors encountered in sport organisations. Journal of Sports Sciences, 30, 349-358. DOI: 10.1080/02640414.2011.633545

Freeman, P., \& Rees, T. (2009) How does perceived support lead to better performance? An examination of potential mechanisms, Journal of Applied Sport Psychology, 21, 429-441. DOI: 10.1080/10413200903222913

Gershgoren, L., Basevitch, I., Filho, E., Gershgoren, A., Brill, Y. S., Schinke, R. J., \& Tenenbaum, G. (2015). Expertise in soccer teams: A thematic inquiry into the role of shared mental models within team chemistry. Psychology of Sport \& Exercise, 24, 128-139. 
698 Gioldasis, A., Stavrou, N., Mitrotasios, M., \& Psychountaki, M. (2016). Cohesion and performance in soccer: A causal model. Sport Science Review, 25, 97112. DOI: $10.1515 / \mathrm{ssr}-2016-0006$

Gould, D., Guinan, D., Greenleaf, C., Medbery, R., \& Peterson, K. (1999). Factors affecting Olympic performance: perceptions of athletes and coaches from more and less successful teams. The Sport Psychologist, 13, 371-394. DOI: $10.1123 /$ tsp.13.4.371

Gould, D., Lauer, L., Rolo, C., Jannes, C., \& Pennisi, N. (2008). The role of parents in tennis success: Focus group interviews with junior coaches. The Sport Psychologist, 22, 18-37. DOI: 10.1123/tsp.22.1.18

Hanton, S., Fletcher, D., \& Coughlan, G. (2005). Stress in elite sport performers: A comparative study of competitive and organizational stressors. Journal of Sports Sciences, 23, 1129-1141. DOI: 10.1080/02640410500131480

Harwood, C. G., Clarke, N. J., \& Cushion, C. (2016). A phenomenological interpretation of the parent-child relationship in elite youth football. Sport, Exercise, and Performance Psychology, 5, 125-143. DOI: $10.1037 /$ spy0000052

Harwood, C. G., Drew, A., \& Knight, C. J. (2010). Parental stressors in professional youth football academies: A qualitative investigation of specialising stage parents. Qualitative Research in Sport, Exercise, and Health, 2, 39-55. DOI: $10.1080 / 19398440903510152$

Høigaard, R., Boen, F., de Cuyper, B., \& Peters, D. M. (2013). Team identification reduces social loafing and promotes social laboring in cycling. International Journal of Applied Sport Sciences, 25, 33-40. 
722 Holt, N. L., \& Tamminen, K. A. (2010). Improving grounded theory research in sport and exercise psychology: Further reflections as a response to Mike Weed. Psychology of Sport \& Exercise, 11, 405-413. DOI: 10.1016/j.psychsport.2009.12.002

Holt, N. L., Tamminen, K. A., Black, D. E., Sehn, Z. L., \& Wall, M. P. (2008). Parental involvement in competitive youth sport settings. Psychology of Sport \& Exercise, 9, 663-685. DOI: 10.1016/j.psychsport.2007.08.001

Knight, C. J., Berrow, S. R., \& Harwood, C. G. (2017). Parenting in sport. Current Opinion in Psychology, 16, 93-97. DOI: 10.1016/j.copsyc.2017.03.011

Kristiansen, E., Halvari, H., \& Roberts, G. C. (2012). Organizational and media stress among professional football players: Testing an achievement goal theory model. Scandinavian Journal of Medicine \& Science in Sports, 22, 569-579. DOI: 10.1111/j.1600-0838.2010.01259.x

Kristiansen, E., Ivarsson, A., Solstad, B. E., \& Roberts, G. C. (2019). Motivational processes affecting the perception of organizational and media stressors among professional football players: A longitudinal mixed methods research study. Psychology of Sport and Exercise, 43, 172-182. DOI: 10.1016/j.psychsport.2019.02.009

Mills, A., Butt, J., Maynard, I., \& Harwood, C. (2012). Identifying factors perceived to influence the development of elite youth football academy players. Journal of Sport Sciences, 30, 1593-1604. DOI: 10.1080/02640414.2012.710753

Moore, L. J., Freeman, P., Hase, A., Solomon-Moore, E., \& Arnold, R. (2019). How stable are challenge and threat evaluations? A generalisability analysis. Frontiers in Psychology. Advance online publication. 
National Deaf Children's Society. (2017). CRIDE 2015 England report. Retrieved from: www.ndcs.co.uk/professional_support/national_data/cride

Podlog, L., Dimmock, J., \& Miller, J. (2011). A review of return to sport concerns following injury rehabilitation: Practitioner strategies for enhancing recovery outcomes. Physical Therapy in Sport, 12, 36-42. DOI: 10.1016/j.ptsp.2010.07.005

Purdue, D. E. J., \& Howe, P. D. (2012). See the sport, not the disability: Exploring the Paralympic paradox. Qualitative Research in Sport, Exercise and Health, 4, 189-205. DOI: 10.1080/2159676X.2012.685102

Roberts, G. A., Arnold, R., Gillison, F., Bilzon, J., \& Colclough, M. (2020). Military veteran athletes' experiences of competing at the 2016 Invictus Games. Disability and Rehabilitation. Advance online publication.

Rumbold, J. L., Fletcher, D., \& Daniels, K. (2018). Using a mixed method audit to inform organizational stress management interventions in sport. Psychology of Sport \& Exercise, 35, 27-38. DOI: 10.1016/j.psychsport.2017.10.010

Rumbold, J., Fletcher, D., \& Daniels, K. (2020). An experience sampling study of organizational stress processes and future playing time in professional sport. Journal of Sports Sciences, 38, 559-567. DOI: $10.1080 / 02640414.2020 .1717302$

Silverman, D. (2006). Interpreting qualitative data: Methods for analysing talk, text, and interaction. London, UK: Sage.

Slater, M. J., Barker, J. B., Coffee, P., \& Jones, M. V. (2015). Leading for gold: Social identity leadership processes at the London 2012 Olympic Games. Qualitative Research in Sport, Exercise and Health, 7, 192-209. DOI: $10.1080 / 2159676 X .2014 .936030$ 
771 Smith, B., Bundon, A., \& Best, M. (2016). Disability sport and activist identities: A qualitative study of narratives of activism among elite athletes' with impairment. Psychology of Sport \& Exercise, 26, 139-148. DOI: 10.1016/j.psychsport.2016.07.003

Smith, B., \& McGannon, K. R. (2018). Developing rigor in qualitative research: Problems and opportunities within sport and exercise psychology. International Review of Sport and Exercise Psychology, 11, 101-121. DOI: 10.1080/1750984X.2017.1317357

Sparkes, A. C., \& Smith, B. (2009). Judging the quality of qualitative inquiry: Criteriology and relativism in action. Psychology of Sport \& Exercise, 10, 491-497. DOI: 10.1016/j.psychsport.2009.02.006

Sport England (2015). Active People Survey (Report No. 9). Retrieved from: https://activepeople.sportengland.org/

Tabei, Y., Fletcher, D., \& Goodger, K. (2012). The relationship between organizational stressors and athlete burnout in soccer players. Journal of Clinical Sport Psychology, 6, 146-165. DOI: 10.1123/jcsp.6.2.146

Tajfel, H. \& Turner, J. C. (1979). An integrative theory of intergroup conflict. In S. Worchel \& W. G. Austin (Eds.), The psychology of intergroup relations (pp. 33-47). Monterey, CA: Brooks-Cole.

Weber, R. P. (1985). Basic content analysis. Beverly Hills, CA: Sage.

Weiler, R., van Mechelen, W., Fuller, C., \& Verhagen, E. (2016). Sport injuries sustained by athletes with disability: A systematic review. Sports Medicine, 46, 1141-1153. DOI: 10.1007/s40279-016-0478-0 
Figure 1: Hierarchical sub-themes

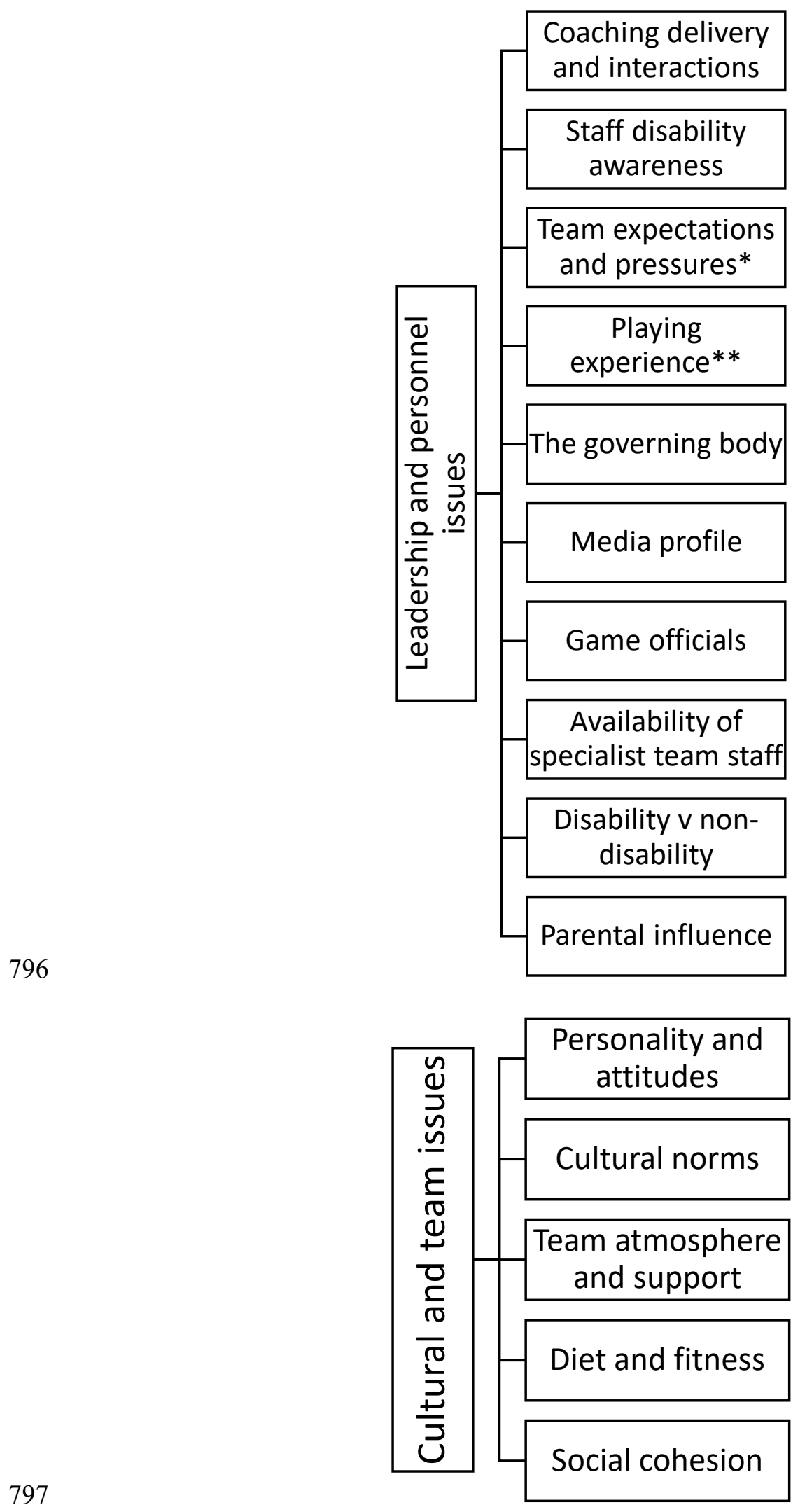



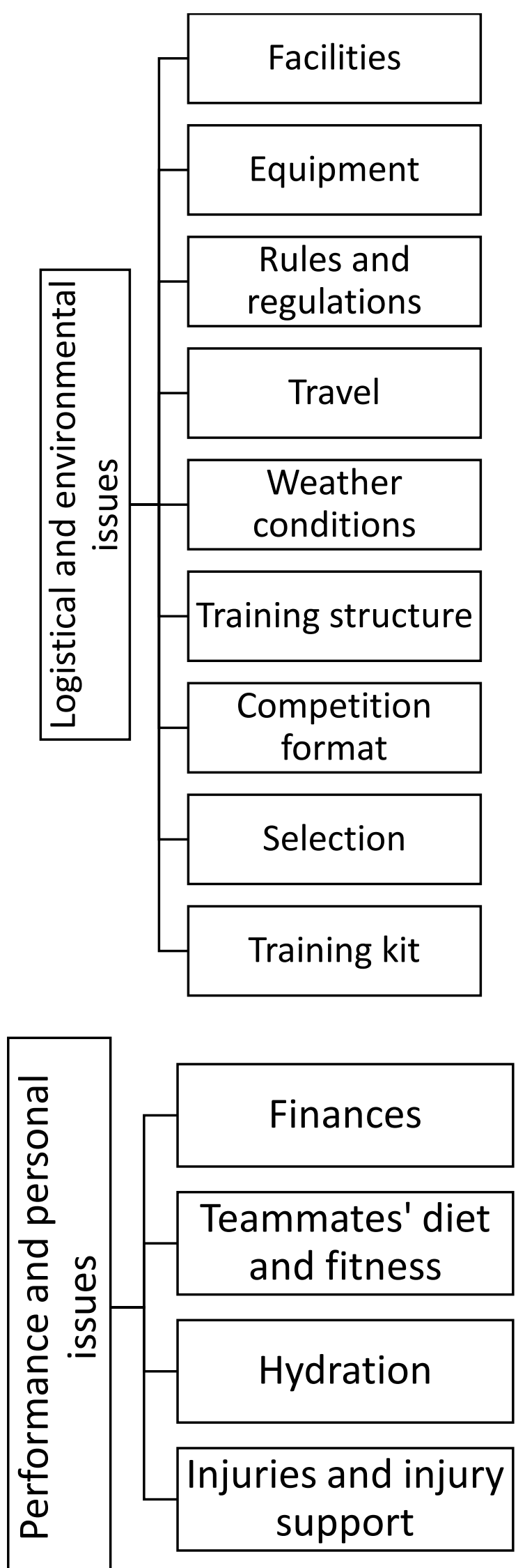
800 * Relates to managing expectations of the NGB to what 'success looks like' for the 801 team comparative to what other nations are able to draw upon pre- and during competition.

$803 * *$ Relates to the experience of playing for the relevant international squad under the 804 management of Head Coach pre- and during competition 